\title{
A GEOGRAFIA DA IMAGINAÇÃO
}

\author{
Kelvin Falcão Klein \\ kelvin.klein@gmail.com
}

O título deste ensaio recupera aquele dado por Guy Davenport a um texto que leu na Universidade do Kentucky em 1978, hoje reunido na coletânea a que dá nome, The Geography of the Imagination, publicada originalmente em 1981. Tratava-se de uma homenagem da universidade ao trabalho de Davenport, que o convidava para a Distinguished Professor Lecture, que naquele ano aconteceu em 8 de março. Na plateia, entre outros membros do corpo docente, estavam "o departamento inteiro de Geografia, um analista junguiano, e alguns fisiologistas que pesquisavam o cérebro"; o próprio Davenport explicou tal heterogeneidade a partir precisamente do título da apresentação: "um título ambíguo faz maravilhas", ele comentou (QUARTERMAIN, 1992, p. 166). Ou seja, uma apresentação sobre a imaginação que já a partir de seu título estabelece uma dinâmica entre estímulo e resposta, expectativa e realidade, contando para isso com a própria capacidade imaginativa da plateia. A linha de abertura do texto é a seguinte: "A diferença entre o Partenon e o World Trade Center, entre Bach e John Philip Sousa, entre Sófocles e Shakespeare, entre uma bicicleta e um cavalo, ainda que explicável pelo momento histórico, necessidade e destino, é, antes de tudo, uma diferença de imaginação" (DAVENPORT, 1997, p. 3).

Em linhas gerais, o ensaio de Davenport trata do problema da transmissão de ideias e imagens pelo tempo e pelo espaço. O evento crítico nesse contexto é a "descoberta" do "Novo Mundo", singularizado 
por Davenport a partir de breves comentários acerca da enormidade imaginativa que foi a viagem da Europa em direção às Américas - "um cartógrafo alemão trabalhando em Paris decidiu traduzir o primeiro nome de Amerigo Vespucci para o latim, por razões conhecidas somente por ele, e chamar a coisa toda de América", comenta ele (DAVENPORT, 1997, p. 4). Tais são as coordenadas da imaginação, geografia e história, a primeira respondendo ao espaço, a segunda ao tempo. Existe, contudo, um contínuo processo de interpolação e sobreposição envolvendo ambas, frequentemente de forma paradoxal. Com isso, Davenport não está apenas indicando a dificuldade de acessar esse atravessamento entre geografia e história na época dos "descobrimentos", por exemplo (e questões correlatas como as de nomeação dos países e do continente, ou detalhes sobre as frotas, os idiomas ou as doenças), está indicando sobretudo que esse exercício depende majoritariamente da imaginação, que seria, nesse caso, não apenas a capacidade de criar imagens, mas a capacidade de rastreálas, resgatá-las e fazer agir sobre elas e a partir delas uma montagem, uma narrativa.

Mas a imaginação histórico-geográfica do presente, "tão íntima quanto o discurso e os costumes", deve ser questionada, estranhada e problematizada, para que nela se inicie uma anamnese do passado "e para rastrear seus caminhos", ou seja, os caminhos da imaginação póstuma, "nós precisamos reeducar nossos olhos", ou ainda, reeducar nossa capacidade de resgatar imagens (DAVENPORT, 1997, p. 5). Para exemplificar esse processo, Davenport escolhe um ensaio de Edgar Allan Poe, "Philosophy of Furniture”, publicado em uma revista norte-americana

${ }^{1}$ Em um dos ensaios de seu livro A nau de Ícaro, o ensaísta português Eduardo Lourenço ressalta a potência imaginativa - absurda, inimaginável, onírica - do gesto de divisão do Novo Mundo por parte de portugueses e espanhóis: "No próximo ano, numa pequena cidade de Castela, Portugal e Espanha celebrarão em conjunto os quinhentos anos que nos separam do Tratado de Tordesilhas. Dois anos antes da data desse tratado, numa jogada ímpar na história, Colombo oferecera à Espanha nascente aquilo que passaria a constituir o Novo Mundo. Quatro anos mais tarde, os portugueses deviam chegar, contornando a África, ao coração do Oriente. Isso bastou para que os dois monarcas europeus - que não figuravam ainda entre os primeiros - tivessem a ideia de traçar no mapa terrestre, simbolicamente, mas com seriedade, duas zonas de exclusividade marítima e de propriedade histórica. Existem, na longa odisseia humana, atos tão memoráveis e tão audaciosos como esse, mas nenhum é tão intrinsecamente onírico" (LOURENÇO, 2001, p. 55). Esse esforço de cartografia da imaginação também envolve um esforço de triangulação simbólica, como será desenvolvido ao longo deste ensaio no comentário sobre Guy Davenport: o Novo Mundo das Américas é lido a partir desses outros dois espaços exóticos e inabarcáveis, a África e o Oriente. 
- a Burton's Gentleman's Magazine - em 1840, que, em sua aparente simplicidade de propósitos - indicações sobre os modos mais adequados para a decoração dos cômodos de uma casa -, descortina uma série de pressupostos envolvidos na relação que a América deveria manter com a Europa, segundo aquilo que imaginava Poe. "Estamos familiarizados com a ansiedade de Poe com relação ao bom gosto", escreve Davenport, "e sobre a fidelidade dos Estados Unidos a modelos europeus. O que queremos ver neste ensaio", ou seja, no ensaio de Poe sobre a mobília, "é uma pista para a estrutura da imaginação de Poe, que Charles Baudelaire pensava ser a maior do século, uma imaginação tão apurada que Paul Valéry disse ser incapaz de cometer um erro" (DAVENPORT, 1997, p. 5).

Pois bem, a partir da leitura atenta de Davenport do ensaio de $\mathrm{Poe}^{2}$, descobre-se que o "bom gosto" professado por Poe em seu texto sobre a mobília - que na superfície se anuncia harmonioso com o estilo vitoriano, por exemplo - é um arranjo complexo de elementos bastante heterogêneos: de uma parte, o grotesco (gravuras de grutas selvagens ou a vista de um lago pantanoso); de outra parte, o clássico (estatuetas gregas de rostos femininos com expressões enigmáticas); e por último, o arabesco (a decoração caligráfica e repetitiva no papel de parede), todos combinados naquilo que Poe pensava ser o cômodo perfeito. É neste mesmo ano de 1840, nos informa Davenport, que Poe publica sua coletânea de contos, Tales of the Grotesque and Arabesque, que para ser ainda mais fiel à imaginação do autor deveria acrescentar um terceiro adjetivo: Tales of the Grotesque, Arabesque, and Classical - o "grotesco" indicando mais o "gótico", ou a estranheza da arte medieval, do que o "monstruoso"; o "arabesco" indicando o intrincado e abstrato estilo decorativo do Islã; e o "clássico" indicando o mundo greco-romano de forma geral. Do particular de seu texto sobre a mobília até o plano geral de sua poética, Poe traduz em linguagem - termos específicos, estratégias retóricas, movimentos

${ }^{2}$ É preciso também indicar outra leitura bastante atenta do ensaio de Poe, incluída em uma ficção que se apropria de forma bastante direta das repercussões de uma geografia da imaginação - me refiro a La literatura nazi en América, livro híbrido do escritor chileno Roberto Bolaño, cuja primeira edição é de 1996. A premissa-guia do livro é já um deslocamento geográfico e imaginativo de amplas proporções: como seriam as formas de vida e de linguagem informadas pelo nazismo no contexto latino-americano? No primeiro capítulo, dedicado à personagem "Edelmira Thompson de Mendiluce", o narrador comenta que o melhor livro de Edelmira chama-se La Habitación de Poe, de 1944, precursor do nouveau roman que estabelece um intenso diálogo e uma ampliação vertiginosa dos procedimentos indicados por Poe em "Filosofia da mobília" (BOLAÑO, 2005, p. 13-24). 
de deslocamento e condensação - a questão complexa do confronto imaginativo entre tempos e espaços heterogêneos.

Depois de apresentar o exemplo do "cômodo ideal" de Poe, mostrando a convivência tensa entre grotesco, arabesco e clássico numa mesma formulação, Davenport prossegue, ampliando seu argumento em direção ao poema "To Helen", também de Edgar Allan Poe. Nos dois primeiros versos, "Helen, thy beauty is to me / Like those Nicaean barks of yore", Davenport detecta um resgate de Safo por parte de Poe, "que já havia comparado a beleza da mulher a uma frota de navios", resgate clássico que é intensificado alguns versos à frente: "Thy Naiad airs have brought me home / To the glory that was Greece / And the grandeur that was Rome". Davenport argumenta que a identidade desse viajante que retorna fica permanentemente cindida entre esses dois registros - Grécia e Roma -, sendo, portanto, inacessível. "Nicaean", por sua vez, não é simples "palavrório", "mas o adjetivo para a cidade de Nice, onde existia um grande estaleiro: a frota de Marco Antônio foi construída lá” (DAVENPORT, 1997, p. 7). A questão é foco de extensa controvérsia, tendo sido o adjetivo já identificado como uma espécie de substituição aos "Feácios" de Homero ("Phaeacian"); como uma grafia alternativa de "Nyseian", referindo-se a Dionísio e à ilha de Nisa; e como uma transformação da palavra grega "Nike", "vitória" (WESTON, 1933, p. 213). O que Davenport ressalta em Poe é a proliferação de sentidos nos termos que escolhe em sua poesia, ou seja, em outras palavras, o rendimento imaginativo que faz circular - para além de seu contexto histórico-geográfico específico.

Nos versos finais do poema, "Lo! In yon brilliant window niche / How statue-like I see thee stand, / The agate lamp within thy hand!", Davenport sinaliza a presença do gótico: "aquela janela com nicho ("window niche") escorregou do norte da Europa; é gótico, um leve tom de gruta nesse poema quase inteiramente clássico" (DAVENPORT, 1997, p. 7). O terceiro elemento vem no verso final, "Ah, Psyche, from the regions which / Are Holy Land!", pois "as palavras de fechamento", escreve Davenport, "Holy Land", "pertencem ao Levante, ao arabesco" (DAVENPORT, 1997, p. 8). Mais uma vez os três elementos são reunidos, disfarçadamente: o clássico no resgate de Safo, o grotesco na visão de uma janela e o arabesco no resgate da imagem da Terra Prometida. Essa dinâmica conflitiva e heterogênea de tempos e espaços é característica de toda a poética de Poe, seja em verso, seja em prosa. Em “The Raven”, continua Davenport, "temos um tom grotesco dominante, com a visão de um Éden arabesco, 'perfumed 
from an unseen censer / Swung by Seraphim whose footfalls tinkled on the tufted floor', e um corvo grotesco pousa em um clássico busto de Palas Atena. Aquele corvo", conclui ele, "era o símbolo na bandeira de Alarico, o Visigodo, cuja tocha sobre Elêusis foi o começo do fim do reino de Palas sobre a mente do homem"; além disso, um conto como "A queda da casa de Usher" poderia ser visto como uma reconstrução grotesca do tema clássico de Orfeu, atravessado por "um moderno entendimento do funcionamento das neuroses, da inexplicável perversidade do comportamento humano" (DAVENPORT, 1997, p. 8).

De onde vêm essas imagens heterogêneas postas em contato por Poe em sua obra? Davenport liga a possibilidade de acesso de Poe a tais elementos ao seu evento fundador, o evento com o qual ele próprio, Davenport, como vimos, inaugurou seu ensaio - as viagens em direção ao Novo Mundo ocorridas durante o Renascimento. O material que serve de matéria-base à imaginação de Poe é aquele trazido por Colombo, e “o Mediterrâneo na época de Colombo", escreve Davenport, "era grecoromano em sua face leste e ao longo da costa norte, aquilo que os historiadores chamam de cultura latina", e, "em sua face oeste e ao longo da costa sul, islâmico"; o "estilo gótico", por outro lado, "tem sua casa no norte da Europa, 'minha Alemanha da alma' como Poe colocou. Ele foi sempre ambíguo com relação à cultura com a qual, ironicamente, ele foi identificado. Morte, corrupção e melancolia são inerentes ao gótico", e elementos cruciais na poética de Poe (DAVENPORT, 1997, p. 8). Mas o que garante essa proliferação imaginativa característica de Poe não é, de forma alguma, um contato direto com esse material tripartite, muito pelo contrário: é precisamente a heterogeneidade e a irregularidade das fontes que gera o esforço extra de Poe de condensar tal desarmonia dentro de um esforço poético que seja, pelo menos na superfície, coeso. De certa forma, essa ênfase final na imaginação não deixa de ser também uma corroboração de uma aposta feita desde o início - não a busca de uma pureza ou essência histórico-geográfica, mas a combinação criativa de vários registros (grotesco, arabesco e clássico).

"A noção de Poe do Islã, que podemos remontar a Byron e Shelley", escreve Davenport, "derivava também de exploradores como Burckhardt, Volney e John Lloyd Stephens”; além disso, “o anjo Israfel não está, como Poe quer que acreditemos, no Corão, mas na introdução de George Sale à sua tradução", pois "a imaginação de Poe estava perfeitamente à vontade em geografias das quais não tinha conhecimento, exceto aquele que sua 
imaginação extraiu de outros escritores", bem como de trabalhos de astronomia, historiografia, botânica, genética, etnografia, entre outros campos (DAVENPORT, 1997, p. 9). Tal proliferação livresca se configurava, evidentemente, como um fenômeno de amplas proporções, tendo como um dos carros-chefe as descobertas realizadas no Egito durante as campanhas napoleônicas na passagem do século XVIII para o XIX. Como escreve Edward Said, “depois da expedição egípcia de Napoleão, a Europa ficou conhecendo o Oriente mais cientificamente, para nele viver com mais autoridade e disciplina como nunca antes" (1990, p. 33). Não só a Europa, acrescentaríamos, mas também as Américas - relembremos, para dar apenas um exemplo, a venda do estado da Louisiana por parte de Napoleão ao governo dos Estados Unidos em 1803. No caso de Poe, é precisamente essa combinação de "autoridade e disciplina" de que fala Said sobre o contato entre "Ocidente" e "Oriente" que chamou a atenção do poeta: a tensa convivência entre cristãos e muçulmanos no Egito, bem como a faceta "racista e tirânica" da "pesquisa arqueológica", também encontraram espaço na reelaboração poética de Poe - em A narrativa de Arthur Gordon Pym, por exemplo, que tempera o imperialismo europeu com doses estadunidenses de polêmica racial (MONTGOMERY, 2013, p. 57).

Eis um ponto do qual Davenport mantém total distância: se a triangulação imaginativa de Edgar Allan Poe passa por uma aclimatação de eventos europeus, deve passar, necessariamente, como o caso do Egito deixa bastante claro, por uma problematização também dessa camada subterrânea de "autoridade e disciplina" que atravessa todo deslocamento histórico-geográfico. Tal problematização gera como desdobramento a reflexão sobre o próprio espaço ocupado por Poe outrora, por Guy Davenport em sua conferência em 1978 e por nós, aqui, hoje - o espaço do "Novo Mundo" e sua emergência histórica marcada, desde o primeiro momento, pela violência. Poe percebe que aquilo que Napoleão realizou outrora no Egito é atualizado frequentemente no cotidiano, não apenas pela ação dos indivíduos, mas pela repercussão textual, discursiva e livresca dessa ação. Tal percepção, no entanto, e como vimos até aqui, não é linear ou homogênea, e a atenção ao padrão mais amplo da violência imperialista é mesclada ao foco meticulosamente restrito das manias e das compulsões individuais. É justamente essa mescla de registros que garante a força da obra de Poe, força essa necessária para a travessia de volta em direção à Europa e em direção à imaginação de outros grandes 
pensadores, como Baudelaire, Nietzsche, Paul Valéry ou Rilke, todos atentos à peculiar dialética entre "realidade amarga" e "mundo imaginativo pessoal” encontrada em Poe (MEYERS, 2000, p. 270).

Ainda que Davenport não explore diretamente esse lado da problematização da "autoridade e disciplina" na obra de Poe, ele coloca na cena de sua argumentação um segundo autor, Oswald Spengler, que, com seu livro $O$ declínio do Ocidente, encaminhará a reflexão para essa direção. De início, a aproximação entre Poe e Spengler se dá a partir das leituras em comum - especialmente Alexander von Humboldt e todo o campo de conhecimentos ao seu redor (a geografia sobretudo). "Como Poe, ele pensava em símbolos", escreve Davenport, e continua: "o valor de $O$ declínio do Ocidente está em sua poesia da visão, sua intuição do nascer, crescer e morrer das culturas", e por cultura "Spengler entendia a energia formadora de um povo, que durava milhares de anos. Uma civilização é a maturidade de uma cultura, e inevitavelmente o seu declínio", o sentimento de Spengler "acerca da exaustão de uma cultura que chega ao fim era como aquele de Poe em 'A queda da casa de Usher' e 'Os crimes da rua Morgue”, "ambas histórias sobre a vulnerabilidade da ordem e dos marcos civilizatórios” (DAVENPORT, 1997, p. 10). Para Davenport, Spengler e Poe não compartilhavam apenas um conjunto de leituras, mas, sobretudo, uma visão de mundo marcada pelo pessimismo e pelo pressentimento de que viviam uma fase de decadência, abandono e erosão.

Tal visão de mundo era compatível também em sua forma de expressão: Davenport escreve que "a intuição mais produtiva de Spengler foi a de dividir as culturas do mundo em três grandes estilos: o apolíneo, ou greco-romano; o fáustico, ou norte-europeu; e o magiar, ou asiático e islâmico", o que nos interessa, conclui ele, "é que as categorias de Spengler são exatamente aquelas de Edgar Allan Poe” (DAVENPORT, 1997, 10), ou seja, o clássico, o grotesco e o arabesco. Ainda que Davenport não o mencione, é possível resgatar outro pensador que utilizava as mesmas categorias e que era, além disso, contemporâneo de Oswald Spengler (1880 - 1936), o historiador da arte Aby Warburg (1866 - 1929). Spengler serve a Davenport para corroborar seu ponto de vista acerca do declínio e da decadência, absorvido em parte também por Poe, ao menos no percurso proposto por Davenport (e poderíamos acrescentar que o fascínio pela decadência talvez corresponda apenas a um terço da imaginação de Poe, ou seja, o segmento grotesco/gótico). Enquanto Spengler investia 
numa intensificação das fronteiras (entre países e entre categorias), Aby Warburg, em um movimento que me parece bem afim ao de Poe, investe em um entrecruzamento criativo das fronteiras e do território - em suma, uma mobilização imaginativa da geografia.

Ao comentar a produção de Warburg durante a I Guerra Mundial, Georges Didi-Huberman ressalta a exaltação da guerra e da manutenção das fronteiras nacionais em autores como Ernst Jünger, Carl Schmitt e Spengler, em contraste com o esforço de Warburg de editar - junto com Giulio Panconelli-Calza - uma revista ilustrada que servia para aproximar fronteiras (DIDI-HUBERMAN, 2010, p. 127). Didi-Huberman também cita uma frase do prefácio de Spengler à primeira edição de A decadência do Ocidente, de 1918 - "espero que este livro não seja de todo indigno dos sacrifícios militares da Alemanha” -, que ecoa no juízo de Davenport: o livro de Spengler, "pensado como um paralelo às campanhas militares da Wehrmacht em 1914-1918" e como um embasamento intelectual de seu desejo de "impor à Europa a regularidade e o destino alemão", alcançou somente "um trágico sentimento de que a história é independente de nossa vontade, ironicamente perversa e um pesadelo" (DAVENPORT, 1997, p. 10).

Assim como Poe, Warburg não se preocupava em delimitar rigorosamente o pertencimento de um elemento a uma categoria, preocupando-se com como cada emergência heterogênea de elementos serve para indicar, sutilmente, soluções técnicas e formais muito específicas. Em um texto central em sua obra, "A arte italiana e a astrologia internacional no Palazzo Schifanoia, em Ferrara”, de 1912, Warburg fala de uma "acepção árabe-helenística" na representação de astros na pintura, rastreando em afrescos realizados na Itália no século XV indicações eruditas provenientes de tratados medievais que mesclavam ao menos três registros, o "sistema árabe", o "sistema ptolemaico" e o "sistema indiano" (WARBURG, 2013, p. 459)3. Ou textos como "O intercâmbio de

${ }^{3}$ A obra de Davenport é bastante extensa, totalizando mais de trinta volumes, e naqueles a que tive acesso não encontrei nenhuma menção a Aby Warburg. Surpreende, no entanto, a menção que Davenport faz ao Palazzo Schifanoia de Ferrara em um ensaio sobre Ezra Pound - este sim, uma de suas principais referências. No ensaio "The House That Jack Built”, Davenport conta que Pound mostrou ao poeta W. B. Yeats, na década de 1920, a reprodução em sépia de um dos afrescos do Palazzo Schifanoia dizendo que aquele seria o modelo para sua obra poética The Cantos. Quarenta anos depois, em Rapallo, Davenport ajuda Pound com o transporte de sua mobília para uma nova casa - e encontra a mesma reprodução dos afrescos mostrada a Yeats, com a inscrição no verso: "Intenção para os Cantos. Acompanhar em paralelo. O Triunfo. As Estações. O contemporâneo" (DAVENPORT, 1997, p. 55-56). 
cultura artística entre Norte e Sul no século XV", de 1905, "A arte flamenga e o início do Renascimento florentino", de 1902, e "O mundo dos deuses antigos e o início do Renascimento no Sul e no Norte”, de 1908, todos ocupados com aquilo que Warburg denomina, neste último texto citado, "migração internacional de imagens", que faz ver o Renascimento como algo que "se deve a uma confrontação, consciente e difícil, com a tradição da Antiguidade tardia e da Idade Média", um conflito "travado com as mesmas forças no Norte e no Sul” (WARBURG, 2013, p. 447).

Warburg, portanto, nos apresenta uma alternativa ao percurso proposto por Davenport a partir de Poe e Spengler, não apenas reforçando a teoria das três categorias/geografias, como ampliando-a. O mapa do Mediterrâneo referido por Davenport para ligar a poética de Poe ao evento de "descoberta" do Novo Mundo é contemplado e trabalhado por Warburg exaustivamente, e, além disso, incorporado a um conjunto de referências que, como vimos, abarcaria também o "sistema indiano", entre outros". Não é apenas o conteúdo das categorias que conta nessa dinâmica, mas sobretudo o modo de relação entre elas - não direcional e teleológico, como em Spengler, mas criativo, heterogêneo e aberto a permutações, como em Poe e Warburg. Encontramos ideias semelhantes a essas em outro contemporâneo de Warburg e Spengler, o também historiador da arte Carl Einstein (1885 - 1940). Einstein abre o conjunto de aforismos

\footnotetext{
${ }^{4}$ No que diz respeito ao esforço de Warburg de acessar geografias imaginativas "ex-cêntricas" e relacioná-las ao arquivo europeu, não se pode deixar de mencionar sua viagem ao sertão dos Estados Unidos e seu contato com os índios Pueblo, Hopi e Zuni, em fins da década de 1890 . Essa viagem gerou a conferência $O$ ritual da serpente, lida em 1923 no sanatório de Kreuzligen, e de publicação póstuma. Carlo Ginzburg comenta esse jogo imaginativo de geografias sobrepostas de Warburg da seguinte forma: "A epígrafe da conferência de Warburg, que foi publicada só depois de sua morte, era uma citação modificada de dois versos da segunda parte do Fausto de Goethe (vv. 7742-3): 'É como folhear um velho livro: / Atenas e Oraibi, todas são primas' (Es ist ein altes Buch zu blättern/Athen, Oraibi, alles Vettern). Em Oraibi, uma aldeia perdida, cavada num rochedo, Warburg havia recolhido testemunhos sobre o rito da serpente dos Pueblo. Em 1920, usara os versos de Goethe, na sua versão autêntica - 'do Harz à Grécia, todas são primas' - como epígrafe do seu grande ensaio sobre Lutero e as profecias astrológicas. Substituindo Harz por Oraibi, o fundador de uma biblioteca dedicada ao estudo do Nachleben da tradição clássica sublinhava a necessidade de estender a análise dos fenômenos culturais para além dos confins não só do Mediterrâneo mas de toda a Europa. O choque com os indígenas pueblo permitiu a Warburg analisar o Renascimento italiano numa perspectiva vigorosa e originalíssima, hoje mais viva do que nunca" (GINZBURG, 2002, p. 135). Essa "necessidade de estender a análise para além dos confins” do Mediterrâneo ganhará eco também no texto de Davenport, como veremos alguns parágrafos mais à frente com o caso do pintor Grant Wood.
} 
que publica no primeiro número da Documents, revista de vanguarda publicada por Georges Bataille entre 1929 e 1930, com uma frase que condensa produtivamente o percurso traçado até aqui em torno da ideia de uma "geografia da imaginação": "a história da arte", escreve Einstein, "é a luta de todas as experiências óticas, dos espaços inventados e das figurações” (EINSTEIN, 1993, p. 17).

Em outras palavras, Einstein postula a história da arte como um espaço de metamorfose, sendo a "história da arte" entendida aí como a história das linguagens que articulam a experiência imaginativa. Temos, em primeiro lugar, a "luta", que abarca a mescla e a heterogeneidade de registros que vimos tanto em Poe como em Warburg - não a estabilidade ou a progressão teleológica, mas a configuração de arranjos potenciais. Em segundo lugar, uma luta que envolve a totalidade das "experiências óticas, dos espaços inventados e das figurações”, mesmo aqueles ainda inacessíveis, seja por limitação histórica, espacial ou temporal. Não é possível falar em declínio ou resolução catastrófica se não se conhece todos os fatores envolvidos; ou ainda, não é possível falar em declínio quando não se sabe que espaços ainda podem ser inventados e que figurações ainda podem ser imaginadas. Não é precisamente isso que está em jogo na reivindicação que Poe faz das referências, sejam grotescas, arabescas ou clássicas? Não é também isso que está em jogo na reivindicação que artistas como Valéry e Baudelaire fazem da obra de Poe? A história da arte é também colocar-se em luta diante daquilo que se apresenta, imaginativamente, como figuração ainda a ser lida, como invenção em processo.

Para Didi-Huberman, as ideias de Einstein exigem "que se pratique a história da arte contra certa noção de história", "contra os modelos positivista, evolucionista e teleológico", pois "ele tentou desenvolver uma dialética não hegeliana - uma concepção da história como 'luta' não apaziguável, irredutível a todo saber absoluto - que é também uma genealogia ao modo nietzscheano" (DIDI-HUBERMAN, 2003, p. 32). Trata-se, portanto, de imaginar uma nova relação com o tempo, o espaço e a história, e nisso, como aponta Didi-Huberman sem sabê-lo, Nietzsche pode servir como um elo de ligação entre Carl Einstein e Edgar Allan Poe, lido pelo primeiro, leitor do segundo (de resto, é uma premissa nietzscheana que Didi-Huberman escolhe para investigar Einstein: a inatualidade). Diante disso, é possível dizer que o Mediterrâneo não é apenas o Mediterrâneo, não se basta ou encerra em seus próprios limites; o Mediterrâneo é também a América e o Novo Mundo, é também o "sistema 
indiano", e, no caso específico de Carl Einstein, é também a África. Na apresentação que escreveà edição brasileira de Negerplastik, originalmente lançado em 1915, Liliane Meffre escreve que Einstein "foi verdadeiramente o descobridor da arte africana, o primeiro teórico ocidental a analisála no plano formal com um olhar livre de todo preconceito, de todo etnocentrismo, e a lhe conferir, através de seus escritos, um estatuto de arte de pleno direito" (MEFFRE, 2011, p. 7).

A imaginação de Poe, ao se apropriar de certas coordenadas simbólicas, faz com que a geografia se expanda, adquirindo uma figuração insuspeita - o mundo greco-romano, o mundo islâmico e o mundo gótico em luta no interior de uma mansão de Boston ("A queda da casa de Usher"). A imaginação de Carl Einstein faz o mesmo, colocando em confronto com as vanguardas europeias de início do século XX a tradição africana - mais uma vez, a expansão inédita de certas coordenadas simbólicas a partir de uma configuração não progressiva e não teleológica do tempo, do espaço e da história. A convivência desses elementos é, evidentemente, tensa, e é a partir dessa dificuldade que as obras de Poe e Einstein ganham força e nos requisitam ainda hoje, fortalecidas por suas próprias incompletudes incompletudes essas que, consequentemente, requisitam a imaginação do tempo presente. Já no final de seu ensaio, Guy Davenport, depois de passar por James Joyce e Grant Wood, afirma que uma "geografia da imaginação" deveria "estender a costa do Mediterrâneo até chegar em Iowa", "Eldon, Iowa", onde Grant Wood realiza seu American Gothic, "uma casa de fazenda que serve de pano de fundo ao duplo retrato de sua irmã Nan e seu dentista, o Dr. B. H. McKeeby" (DAVENPORT, 1997, p. 12). No movimento que vai do geral (o Mediterrâneo) até o mais vertiginoso particular (o dentista de Grant Wood), Davenport condensa a própria potência da imaginação, que, em sua dinâmica disruptiva e heterogênea, se mescla à potência da linguagem poética - pois deslocamento e condensação são os procedimentos indispensáveis para a reunião do Mediterrâneo com Iowa ou com o Benin.

Ao comentar a pintura de Grant Wood, Davenport apresenta outra faceta de sua reflexão sobre a geografia da imaginação. Agora não se trata apenas de rastrear as apropriações simbólicas e formais ao longo do tempo e do espaço, ou os métodos de transmissão e retransmissão; no caso de Wood, e no caso ainda mais específico de American Gothic - o casal magro diante de uma casa, ele de óculos e um forcado na mão, ela de olhos baixos e avental -, é preciso um esforço de esquecimento diante das múltiplas 
camadas de tempo e espaço ali acumuladas. Diante de American Gothic, escreve Davenport, certamente se referindo mais enfaticamente aos norteamericanos, "estamos cegados pela familiaridade e pela paródia" (1997, p. 12). A partir daí, o movimento é inverso mas complementar: é preciso desnaturalizar o olhar, abandonar as impressões que nos chegam mais facilmente e permitir a abertura ao trabalho imaginativo. Tal trabalho imaginativo, no caso de American Gothic, consiste em suspender as premissas daquilo que se conhece e trasladar esse "conhecido" em direção a um tempo/espaço inaudito, inesperado - o inverso, portanto, daquilo que faz Carl Einstein ao levar a África em direção às vanguardas europeias.

Inverso, sim, mas como dito acima, complementar. A dialética de Einstein, "não hegeliana" na medida em que isso é possível, como aponta Didi-Huberman, que "está mais próxima do sentido benjaminiano da 'imagem dialética”, não quer nem tornar primitiva a arte moderna, nem modernizar a arte africana, pois "não manifesta uma estase, uma existência fixa, mas o movimento próprio da exigência", exigência "de um ponto de vista que se poderia dizer 'sintético', sob a condição de não se entender por este adjetivo a clausura autopacificante de um saber que acreditaria ter chegado a seus fins", pois "a síntese, neste movimento, é apenas uma coisa incompleta, frágil, sempre em estado de inquietude: é uma sínteseabertura" (DIDI-HUBERMAN, 2003, p. 43)5. A clausura de que fala DidiHuberman tem relação com a familiaridade de que fala Davenport, familiaridade que dificulta a exposição de detalhes significantes não apenas no quadro de Grant Wood, como também em inúmeros textos e imagens congelados em "existências fixas". O gesto crítico a ser realizado diante desse cenário é exercitar uma imaginação que possa dar conta de vias de saída de tal fixidez, instaurando, finalmente, a "síntese-abertura".

5 Um trabalho que ainda precisa ser feito é relacionar tal cenário de apropriação do contexto africano por Carl Einstein, e sua visada "não hegeliana", com o livro de Susan Buck-Morss, Hegel, Haiti, and Universal History, que se apresenta, em grande medida, como um esforço de ampliação da geografia imaginativa da crítica - não apenas Hegel falhou em saber ver o Haiti, argumenta Buck-Morss, mas também Simon Schama em sua história econômica da Holanda, que falhou em saber ver a África e o tráfico de escravos (e como Buck-Morss faz esse conjunto de incapacidades reverberar em textos e imagens, do passado e do presente). E Buck-Morss ressalta que a urgente ampliação do escopo geográfico da crítica é uma tarefa da imaginação: "ao invés de defender a ideia de campos intelectuais, o foco do debate acadêmico deveria ser a ampliação de nossa imaginação histórica", pois "fatos deveriam inspirar a imaginação mais do que limitá-la" (BUCKMORSS, 2009, p. 14); "os limites de nossa imaginação devem ser desfeitos tijolo por tijolo, rompendo o enclausuramento cultural que pré-determina o sentido do passado de um modo que nos prende ao presente" (p. 149). 
Para desvencilhar American Gothic de sua existência fixa, Davenport começa por uma genealogia da pose do casal: homem e mulher lado a lado, de perto, evocando uma antiga iconografia egípcia, com o faraó e sua esposa servindo como mediadores entre o céu e a terra; evocando casais etruscos em terracota, e, finalmente, o retrato de van Eyck do casal Arnolfini e o autorretrato de Rubens com sua esposa Helena - com um componente contemporâneo de Wood que Davenport faz questão de frisar: o enquadramento do casal é também aquele possibilitado pela câmera fotográfica Brownie. Foi justamente "essa tradição flamenga de pintar pessoas comuns com honra e precisão", acrescenta Davenport, "que fez Grant Wood abandonar Montparnasse, onde passou dois anos na década de 1920 tentando ser um pós-impressionista americano, e voltar para Iowa, para ser nosso Hans Memling”, e finaliza com um paralelo: “se Van Gogh pudesse perguntar, 'Onde está meu Japão?', e receber de Toulouse-Lautrec a resposta de que era na Provença, Wood perguntou a si mesmo onde era sua Holanda e a encontrou em Iowa" (DAVENPORT, 1997, p. 14). Daí a necessidade de se ampliar a costa do Mediterrâneo até Iowa, incorporando em seu fluxo a tradição flamenga, Montparnasse, o registro dinástico do Egito e o enquadramento da câmera Brownie.

Toda imagem e texto, ao encontrar seu ponto de ancoragem na história da arte, entra numa dinâmica de constante confronto com outros textos e imagens. A cadência desse confronto é dada pelos diferentes modos de articulação dos procedimentos formais - em American Gothic, por exemplo, temos o encontro de um enquadramento fotográfico com uma meticulosa pincelada flamenga; nos textos de Poe, o encontro sempre tenso do arabesco, do clássico e do grotesco. Diante disso, a geografia da imaginação consiste em pelo menos dois movimentos, que poderíamos denominar complicatio e explicatio. No primeiro movimento há uma internalização da heterogeneidade dos elementos, um condensação (com) das dobras (pli) que tornam possível o artefato ou gesto artístico, uma intensificação da experiência em prol de uma criação - seja ela American Gothic, o poema “To Helen” ou o Palazzo Schifanoia em Ravena. O segundo movimento consiste no imediato contraponto do primeiro, ou seja, o desenrolar (ex) das dobras ( $p l i)$, a proposição de um percurso que dê conta das minúcias pouco acessíveis da constituição do artefato ou gesto artístico. Exemplo disso é o esforço de Guy Davenport para dissecar o que pode haver de egípcio ou de flamengo em American Gothic, ou quais termos do poema de Poe evocam o Oriente; ou ainda o trabalho 
de Aby Warburg ao redor dos tratados astrológicos árabes e indianos que estimularam a imaginação de dois pintores italianos no século XV pintores esses que dividiram seus afrescos também em três categorias: no alto, os deuses do Olimpo e seus símbolos; no meio, os decanos das casas zodiacais e seus símbolos; abaixo, o cotidiano de Ferrara, seus habitantes, seus hábitos e os bons atos do soberano, Borso d'Este.

Essa última observação nos permite recordar a validade da hipótese de Davenport acerca da triangulação simbólica em Poe, mas recordar igualmente suas limitações, dimensão que fica mais evidenciada com seu resgate de Oswald Spengler. Com relação a Spengler, não foi preciso um deslocamento geográfico muito pronunciado para encontrar contemporâneos seus que investiam não na decadência ou no afastamento, mas na produtividade de outros horizontes (a África, o sistema indiano) e na aproximação de fronteiras. Se o movimento geográfico não se mostra exaustivo (já que Spengler, Warburg e Einstein moraram, durante vários períodos de seus vidas, a poucos quilômetros de distância uns dos outros), talvez o movimento da imaginação compense, pois certamente eram três mundos radicalmente distintos que estavam em jogo em seus respectivos trabalhos. Mas é importante frisar que não há complicatio sem uma explicatio anterior, ainda que sutil, e que toda explicatio perdura na história como um enigma, uma provocação àqueles que a ela se dirigem. Não é precisamente a explicatio de Davenport que nos move aqui? São os meandros de seu argumento que movem as objeções e referências feitas aqui neste ensaio, cujo objetivo final é o de desdobrar e ampliar as dobras das intuições de Davenport. Se algo pode ser estabelecido acerca da geografia da imaginação é que se trata de uma cartografia em aberto, feita menos de existências fixas e mais de síntesesaberturas.

\section{REFERÊNCIAS BIBLIOGRÁFICAS}

BOLAÑO, Roberto. La literatura nazi en América. Barcelona: Seix Barral, 2005.

BUCK-MORSS, Susan. Hegel, Haiti, and Universal History. Pittsburgh: University of Pittsburgh Press, 2009.

DAVENPORT, Guy. The Geography of the Imagination. Boston: Nonpareil Books, 1997. 
DIDI-HUBERMAN, Georges. Atlas ¿Cómo llevar el mundo a cuestas?. Tradução ao espanhol Maria Dolores Aguilera. Madri: Museo Nacional Centro de Arte Reina Sofia, 2010.

DIDI-HUBERMAN, Georges. O anacronismo fabrica a história: sobre a inatualidade de Carl Einstein. Tradução de Maria Squeff. In: ZIELINSKY, Mônica. Fronteiras: arte, crítica e outros ensaios. Porto Alegre: Editora da UFRGS, 2003, p. 19-53.

EINSTEIN, Carl. Ethnologie de l'art moderne. Liliane Meffre (ed.). Marselha: André Dimanche, 1993.

GINZBURG, Carlo. Relações de força: história, retórica, prova. Tradução de Jônatas Batista Neto. São Paulo: Companhia das Letras, 2002.

LOURENÇO, Eduardo. A nau de Ícaro e Imagem e miragem da lusofonia. São Paulo: Companhia das Letras, 2001.

MEFFRE, Liliane. Apresentação. Tradução de Fernando Scheibe. In: EINSTEIN, Carl. Negerplastik (escultura negra). Liliane Meffre (org.). Tradução de Fernando Scheibe e Inês de Araújo. Florianópolis: Editora da UFSC, 2011.

MEYERS, Jeffrey. Edgar Allan Poe: his life and legacy. Nova York: Cooper Square Press, 2000.

MONTGOMERY, Travis. The Near East. In: HAYES, Kevin (ed.). Edgar Allan Poe in context. Nova York: Cambridge University Press, 2013, p. 53-62.

POE, Edgar Allan. Filosofia do mobiliário. In: Poesia e Prosa. Trad. Oscar Mendes. São Paulo: Editora Globo, 1944, pp. 296-30o.

QUARTERMAIN, Peter. Disjunctive poetics: from Gertrude Stein and Louis Zukofsky to Susan Howe. Cambridge, Mass.: Cambridge University Press, 1992.

SAID, Edward W. Orientalismo: o Oriente como invenção do Ocidente. Tradução de Tomás Rosa Bueno. São Paulo: Companhia das Letras, 1990.

SPENGLER, Oswald. A Decadência do Ocidente. Trad. Herbert Caro. Brasília: Editora da $\mathrm{UnB}, 1982$.

WARBURG, Aby. A renovação da Antiguidade pagã: contribuições científico-culturais para a história do Renascimento europeu. Tradução de Markus Hediger. Rio de Janeiro: Contraponto, 2013.

WESTON, Arthur Harold. The "Nicean Barks" of Edgar Allan Poe. In The Classical Journal. Northfield: The Classical Association of the Middle West and South. Vol. 29, № 3, dezembro de 1933, pp. 213-215. 